\title{
Changes in Feeding Behavior as Possible Indicators for the Automatic Monitoring of Health Disorders in Dairy Cows
}

\author{
L. A. González, ${ }^{\star} \nmid \ddagger^{1}$ B. J. Tolkamp, ${ }^{*}$ M. P. Coffey, ${ }^{\star}$ A. Ferret, $† \ddagger$ and I. Kyriazakis ${ }^{\star} \S$ \\ ${ }^{*}$ Research and Development Division, Scottish Agricultural College, The Kings Buildings, Edinburgh EH9 3JG, United Kingdom \\ †Departament de Ciència Animal i dels Aliments, and \\ $\ddagger$ Animal Nutrition, Management, and Welfare Research Group, Universitat Autònoma de Barcelona, 08193 Bellaterra, Spain \\ §Veterinary Faculty, University of Thessaly, PO Box 199, 43100 Karditsa, Greece
}

\begin{abstract}
Changes in short-term feeding behavior of dairy cows that occur with the onset of the health disorders ketosis, acute locomotory problems, and chronic lameness were investigated using data collected during previous experiments. The objective of the study was to describe and quantify those changes and to test their suitability as early indicators of disease. Feed intake, feeding time, and number of daily feeder visits were recorded with computerized feeders. Ketosis in 8 cows was characterized by rapid daily decreases in feed intake $[-10.4 \mathrm{~kg}$ of fresh matter $(\mathrm{FM})$ ], feeding time $(-45.5 \mathrm{~min})$, and feeding rate $(-25.3 \mathrm{~g}$ of $\mathrm{FM} / \mathrm{min})$ during an average of $3.6 \mathrm{~d}$ before diagnosis by farm staff. Acute locomotion disorders in 14 cows showed smaller daily decreases in feed intake $(-1.57 \mathrm{~kg}$ of $\mathrm{FM})$ and feeding time $(-19.1$ $\mathrm{min})$, and a daily increase in feeding rate $(+21.6 \mathrm{~g}$ of $\mathrm{FM} / \mathrm{min}$ ) during an average of $7.7 \mathrm{~d}$ from onset to diagnosis. The effects of chronic lameness on short-term feeding behavior were assessed by analyzing changes during the $30 \mathrm{~d}$ before and $30 \mathrm{~d}$ after all cows were checked for foot lesions and trimmed, and cows were classified as either lame $(n=81)$ or not lame $(n=62)$. During the $30 \mathrm{~d}$ before trimming, cows classified as lame showed significant changes in daily feeding time, number of daily visits, and feeding rate, but nonlame cows did not. In lame cows, the observed daily changes (slope) for the $30 \mathrm{~d}$ before and the $30 \mathrm{~d}$ after trimming were -0.75 and $+0.32 \mathrm{~min} / \mathrm{d}$ for daily feeding time, -0.35 and +0.31 for daily number of visits, and +0.77 and $-0.35 \mathrm{~g} / \mathrm{min}$ for feeding rate, respectively. These changes in feeding behavior were not different among cows consuming low or high forage rations. Daily feeding time was the feeding characteristic that changed most consistently in relation to the studied disorders. A simple algorithm was used to identify cows whose
\end{abstract}

Received July 19, 2007.

Accepted November 21, 2007.

${ }^{1}$ Corresponding author: LucianoAdrian.Savone@uab.es daily feeding time was lower than the previous 7-d rolling average minus 2.5 standard deviations. The algorithm resulted in detection of more than $80 \%$ of cows with acute disorders at least $1 \mathrm{~d}$ before diagnosis by farm staff. Short-term feeding behavior showed very characteristic changes with the onset of disorders, which suggests that a system that monitors short-term feeding behavior can assist in the early identification of sick cows.

Key words: dairy cow, feeding behavior, health monitoring

\section{INTRODUCTION}

Health problems in dairy cows are important for farmers because they result in production losses (Fourichon et al., 1999; Rajala-Schultz et al., 1999), lead to treatment costs (Kossaibati and Esslemont, 1997), and are detrimental to animal welfare (FAWC, 1997). Mastitis and lameness are considered to be, economically, the most important diseases of dairy cows (Kossaibati and Esslemont, 1997). Economic losses are due to premature culling, reduced milk yield and quality, veterinary treatment, and increased labor. Clinical mastitis reduced milk yield by 65 to $160 \mathrm{~kg}$ of milk per occasion, whereas for mastitis in one quarter only the loss was $13 \mathrm{~kg}$ (Bareille et al., 2003). Lameness decreased milk yield by up to $310 \mathrm{~kg}$ per lactation (Rajala-Schultz et al., 1999) and has caused serious concerns about animal welfare (FAWC, 1997; Whay et al., 1998). In addition, metabolic disorders such as ketosis can produce moderate to large reductions in milk yield and feed intake over a short time (Fourichon et al., 1999; Rajala-Schultz et al., 1999; Bareille et al., 2003).

The incidence of health disorders has increased, possibly because they are associated with increased milk yield and production stress (Fleischer et al., 2001). Mortality rates also increased from 2 to $3.5 \%$ in $10 \mathrm{yr}$, with locomotor disorders as one of the main causes (Thomsen et al., 2004). Veterinary treatments and management changes are generally more effective the earlier they 
are initiated in the disease process. Therefore, early identification of sick animals could improve animal welfare (by increasing treatment effectiveness) and reduce its cost. However, early identification of health problems in dairy cows is difficult and generally relies on subjective identification by farm personnel. By definition, subclinical disease would escape diagnosis but may lead to serious problems later. Development of dairy farming in many countries could make early identification even more problematic because human-animal interaction is expected to decrease. This is related to the establishment of intensive production systems with large numbers of cows per herd and the use of automatic milking units and feeders that limits personnel requirements (Frost et al., 1997). Under such conditions, tools to monitor the health status of cows can assist farm staff to identify diseased cows earlier. The implementation of such tools via computer-controlled programs can become valuable instruments for on-farm use to improve animal welfare and lower production losses.

Automated cow status monitoring for health disorders and heat detection was developed recently. Sensors that measure milk yield, temperature, and electrical conductivity, as well as the animal's activity with pedometers allow the identification of cows that are suffering from disease or that are in estrus (Frost et al., 1997). Several researchers have also dealt recently with feeding behavior measures to monitor the health status of cattle. Radiofrequency technology was used to measure time at the feed bunk, which allowed the identification of morbid beef cattle (due mainly to bovine respiratory disease) $4 \mathrm{~d}$ earlier than identification by experienced personnel (Quimby et al., 2001). Similarly, cows that subsequently developed clinical metritis spent less time feeding than their healthy counterparts (Urton et al., 2005; Huzzey et al., 2007). In veal calves fed with automatic milk feeders the number of unrewarded and rewarded visits (Svensson and Jensen, 2007) or the rate of milk intake were considered as good indicators of health status due mainly to diarrhea and bovine respiratory disease (Maatje et al., 1993). Changes in feeding behavior may, therefore, be useful to identify health problems in cattle.

During experiments conducted at the Langhill Dairy Cattle Research Centre, we have observed certain characteristic changes in the short-term feeding behavior of individual animals in relation to specific health problems. A systematic analysis of those behavioral changes could be the basis of a system that assists animal caretakers in the early identification of disorders before overt clinical symptoms become evident. Therefore, the first objective of the present study was to identify characteristic changes in short-term feeding behavior asso- ciated with the onset of health disorders and to quantify those changes. The evaluation of the suitability of those changes as a diagnostic tool for the early identification of health problems in group-housed dairy cows was our second objective.

\section{MATERIALS AND METHODS}

All cows that were used in the experiments described were monitored under the regulations established by the Animal Experiments Committee of the Scottish Agricultural College.

\section{Animals, Feeding, and Management}

The present study was based on data collected during previous experiments conducted at the Langhill Dairy Cattle Research Centre between 1995 and 1998 and during 2001. A detailed description of the computerized feeders that were used to collect the data (Tolkamp and Kyriazakis, 1997, 1999) and descriptions of the experiments carried out in one yard equipped with 28 feeders and 52 cubicles during the 1995 to 1998 period have been reported previously (Tolkamp et al., 1998a,b, 2000,2002 ). The same yard and an additional similar one equipped with 20 feeders of the same type housed the cows that provided the data obtained during 2001. These cows were part of the long-term genotype by environment experiment as described by Veerkamp et al. (1995).

Briefly, Holstein-Friesian lactating cows were housed in groups of up to 50 animals in a yard that consisted of 2 cubicle rows separated by a passage. A single row of feeders occupied one side of the yard. Water was provided in 2 troughs located at each extreme end of the feeding passage. Cows were maintained continuously in the yard except for normal farm routine periods such as milking (at about 0600 and $1600 \mathrm{~h}$ ) and occasional hoof trimming and pregnancy diagnosis. Some cows suffering from health disorders, mainly acute ones, were moved to hospital pens for veterinary treatment. The length of this time out of the group was variable and dependent on the disease diagnosis and veterinary advice.

Cows received $0.5 \mathrm{~kg}$ of concentrates during milking and the rest of the feed was given as TMR with different proportions of concentrate and forage. When the TMR contained between 22 and $30 \%$ concentrate it was classified as low-forage ration, and that containing between 8 and $13 \%$ of concentrate was classified as high-forage ration. Mixed grass silage was the main forage source in all rations. About three-fourths of the daily feed allowance was given in the morning (between 0800 and $0930 \mathrm{~h}$ ) and the remainder was added to the feeders 
during the afternoon milking. Feeding management was ad libitum with a target of $10 \%$ orts.

The TMR was offered in roughage intake control feeders (Insentec B.V., Marknesse, the Netherlands) that were connected to a personal computer. All cows were provided with collar transponders that allowed identification when a cow approached the feeder and the pneumatically operated door was opened. Cow identification, feeder number, bin weight, and time at the start and at the end of each visit were recorded as described by Tolkamp and Kyriazakis (1997). Starting and ending times of visits were recorded to the nearest second for data recorded between 1995 and 1998 and the meal criterion to group visits into meals was determined for each cow as described by Yeates et al. (2001). Starting and ending times were recorded to the nearest minute for data collected during 2001 and a pooled meal criterion of 26 min was used for these data.

\section{Health Records}

Health disorders were diagnosed by veterinarians and logged into the system by the farm technician according to a list of putative diseases. Registered health problems were related to reproduction, udder health, locomotion, and respiratory, metabolic, and digestive disorders. They were further differentiated by codes to allow a better description of the disorder. Our main focus was on locomotion, udder health, and metabolic disorders because of the number of animals affected and the probability of detecting them by a monitoring system. Udder health codes allowed for the distinction between mastitis due to Escherichia coli, summer mastitis, mastitis in one quarter, milk reduced, high SCC, teat or udder injury, and edema. The only metabolic disorder presented herein was ketosis, which was diagnosed through clinical detection by a veterinarian. Acute lameness problems were recorded after examination of the feet when an animal was observed to be lame by farm personnel. In addition, the feet of all cows present were periodically trimmed and the health records showed which cows were trimmed and whether any disorders were diagnosed and treated. The data of lame as well as nonlame cows obtained via this route were included in the analyses of chronic lameness. Locomotion disorders were classified in one of several categories that allowed the description of the type of lesion observed as well as the foot affected, similar to that described by Shearer et al. (2002). The main locomotion disorders included foul-of-foot, laminitis, underrun heel or sole, sole ulcer, wall abscess, digital dermatitis, white line disease, interdigital granuloma, punctured sole, and sand cracks. Depending on the health disorder, cows were treated as recommended by the veterinarian and moved to the hospital pen if necessary. Seven out of the 8 ketosis cases finally included in the analysis received veterinary treatment. Ten out of the 14 acute locomotion disorders received veterinary treatment with a range of drugs, whereas 4 cows did not receive any veterinary treatment. All cows, lame and nonlame, used for the analysis of chronic locomotion disorders were trimmed and inspected on the same day. Only 2 lame cows were both trimmed and treated with drugs. Data were excluded from analysis when confounding effects, such as treatment change, start or end of lactation, or another ailment, were present within $10 \mathrm{~d}$ of the occurrence of an acute disorder or within $30 \mathrm{~d}$ of chronic cases of lameness. The numbers deleted for this reason were 10 out of 18,9 out of 23,18 out of 105 , and 24 out of 105 cases of ketosis, acute lameness, pretrimming chronic lameness, and posttrimming chronic lameness analyses, respectively.

\section{Statistical Analysis}

Acute disorders were identified in a preliminary analysis as those that were associated with rapid changes in feeding behavior characteristics. Sufficient data were available for analysis of ketosis and acute locomotion problems. The preliminary analysis also showed that daily feeding time was the feeding characteristic that changed most consistently as a result of any disorder analyzed here. This characteristic was, therefore, chosen to identify the onset of the acute disorders. A 7-d rolling average and SD for feeding time was calculated for each day based on the data collected previously. The last day before diagnosis that the feeding time was in the normal range of rolling average \pm 1.5 SD was identified. This day and all data between this day up to and including the day of diagnosis (assigned $d 0$ ) were included in the analysis. Fresh feed intake, daily feeding time, feeding rate, and number of meals and visits per day for each disorder were analyzed with a mixed-effects linear regression model using PROC MIXED of SAS (v. 9.1, SAS Institute Inc., Cary, NC). The model contained the fixed effect of day relative to diagnosis as a covariate (continuous variable), which was also a random effect subjected to the cow, as well as the random intercept. The repeated measures of day were modeled as autoregressive order one or unstructured for each cow based on the best fit assessed with the Bayesian information criterion.

Analyzed chronic disorders were restricted to locomotion problems that caused lameness and that were identified at the time of hoof trimming. Cows were classified as either nonlame (no locomotion disorders recorded) or lame when any kind of ailment concerning locomotion was recorded, independent of the type of diagnosis 
or the number of feet affected. To study effects of chronic locomotion problems on feeding behavior, 2 separate analyses were carried out, the first covering the $30 \mathrm{~d}$ before trimming, and the second the $30 \mathrm{~d}$ after trimming. Cows classified as lame and nonlame that did not suffer from any other disorder during this periods and had feeding behavior records were included in these analyses. The mixed-effects models contained the fixed categorical effects of lactation number (7 levels), year (3 levels), type of ration (2 levels), lameness status (2 levels), and the type of ration $\times$ lameness status interaction. Type of ration was classified as either low or high as described previously. Day relative to hoof trimming and checking ( -30 to $0 \mathrm{~d}$ or 0 to $30 \mathrm{~d}$ ) was set as a covariate, and the day $\times$ forage content, the day $\times$ lameness status, and the day $\times$ forage content $\times$ lameness status allowed us to test for differences among the slopes fitted to each cow at each level of those factors. Therefore, differences between the slopes at each level of the categorical variables were first tested, and, subsequently, those slopes were quantified and tested for difference from zero. The repeated measures of day and the intercept were modeled for each cow within disease through the random statement. The Satterthwaite's approximation method was used for the calculation of the degrees of freedom.

To investigate how a simple algorithm could contribute to the detection of acute disorders, a "normal range" was calculated on the basis of a rolling average of $7 \mathrm{~d}$ $\pm X$ times the $\mathrm{SD}$ (with values for $X$ ranging from 1.5 to 5). The first day that a value occurred outside this range was determined for cows with recorded cases of ketosis or acute lameness. It was assumed that this would result in a warning by an automated early detection system one day later. The difference between this day and the day the animal was actually diagnosed by farm staff was then calculated as an estimate of how much earlier diagnosis would have occurred had such a warning system been in place.

\section{RESULTS}

\section{Quantifying Effects of Disorders on Short-Term Feeding Behavior Characteristics}

Ketosis. When cows were diagnosed with ketosis, feed intake was already decreased dramatically by $10.38 \mathrm{~kg}$ of fresh matter $(\mathbf{F M}) / \mathrm{d}$ during the previous $3.6 \pm 0.9 \mathrm{~d}$ (Table 1). Similarly, daily feeding time decreased by $45.5 \mathrm{~min} / \mathrm{d}$ and feeding rate by $25.3 \mathrm{~g}$ of FM/ min per d before diagnosis. Data from 2 typical cows showing these changes previous to diagnosis are shown in Figure 1. The number of days before the day of diagnosis over which the changes were observed ranged from 3 to $5 \mathrm{~d}$ for daily feeding time. The trend of decreas-
Table 1. Regression coefficients and standard errors resulting from linear regressions of feeding behavior characteristics on number of days before diagnosis by farm staff of cows identified as suffering from ketosis or acute locomotory disorders

\begin{tabular}{lccc}
\hline & $\begin{array}{c}\text { Regression } \\
\text { coefficient }\end{array}$ & $\mathrm{SE}$ & $P$-value \\
\hline Disease & & & \\
Ketosis (n = 8) & -10.38 & 2.63 & $<0.01$ \\
Feed intake, $\mathrm{kg}$ of FM 1 /d & -45.54 & 12.52 & $<0.01$ \\
Feeding time, min/d & -62.53 & 21.19 & 0.02 \\
Meal time, min/d & -25.26 & 13.22 & 0.09 \\
Feeding rate, g of FM/min & -0.676 & 0.262 & 0.03 \\
Meals, n/d & -11.25 & 4.84 & 0.05 \\
Visits, n/d & & & \\
Acute locomotory disorders (n $=14)$ & -1.57 & 0.58 & 0.03 \\
Feed intake, kg of FM/d & -19.10 & 4.64 & 0.007 \\
Feeding time, min/d & -33.40 & 9.86 & 0.004 \\
Meal time, min/d & 21.61 & 1.88 & $<0.001$ \\
Feeding rate, g of FM/min & -0.226 & 0.078 & 0.01 \\
Meals, n/d & -10.50 & 4.31 & 0.03 \\
Visits, n/d & & & \\
\hline
\end{tabular}

${ }^{1} \mathrm{FM}=$ fresh matter

ing feed intake was also reflected in the decreasing number of meals and visits (Table 1).

Acute Locomotion Disorders. Fourteen cases of acute locomotion disorders were analyzed, of which the veterinary diagnosis classified 1 with a general locomotion problem due to a spinal abscess, 2 with foul-of-foot, 5 with a sole ulcer, 2 with puncture sole with pus, 2 with leg abscess and swollen hock, 1 with toe abscess, and 1 with white line disease. There was a small but significant decrease in feed intake for acute locomotion disorders, with a large decrease in feeding time and a sharp increase in feeding rate as the day of diagnosis approached (Table 1). Time in the feeder decreased by 19 min every day as the day of diagnosis approached over an average of $7.7 \pm 2.1$ (range from 3 to 15 ) $d$. The number of meals and the number of visits to the feeders also decreased with time. However, considerable variation was observed in the changes in short-term feeding behavior and in the number of days during which these changes occurred. Panels A and D of Figure 2 show data for 2 cows with different locomotion disorders that did not change feed intake except for the last 1 or $2 \mathrm{~d}$ before diagnosis. The slope showing the decrease in feeding time throughout the days was quite different between both cows, being 3 -fold greater and of shorter duration for sole ulcer (Figure 2B) compared with the general locomotion disorder (Figure 2E). This was the result of similar decreases, around $65 \%$, over $6 \mathrm{~d}$ in the former cow (Figure 2C) but over $13 \mathrm{~d}$ in the second (Figure 2F). In both cases, the changes in feeding time were mirrored by changes in feeding rate, resulting in almost constant daily intakes.

Udder Health Disorders. Udder problems were recorded in 30 cows with suitable data for analysis. Two 

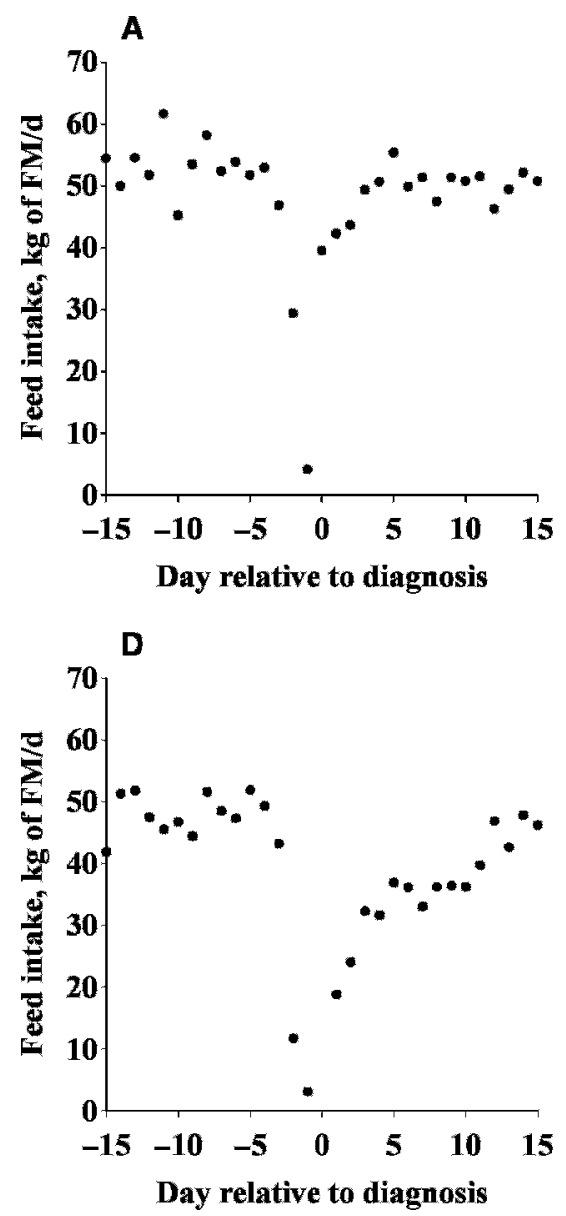

B

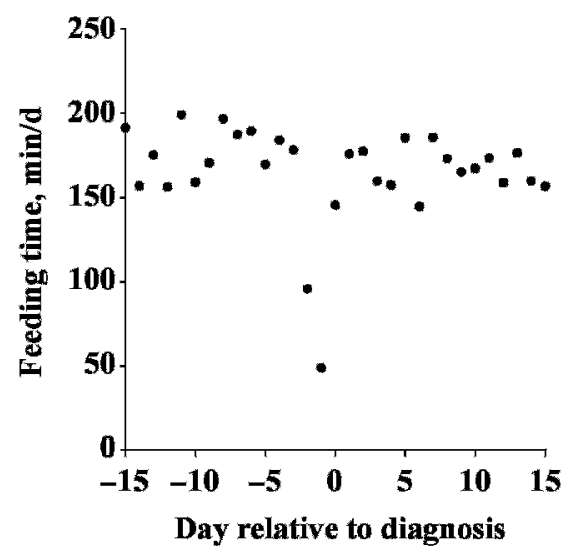

E

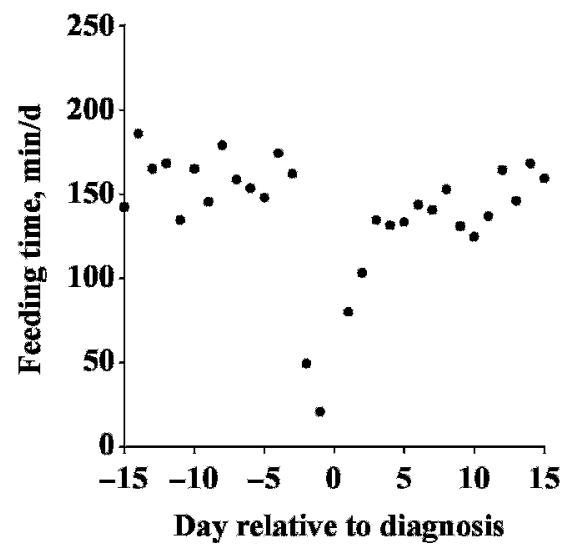

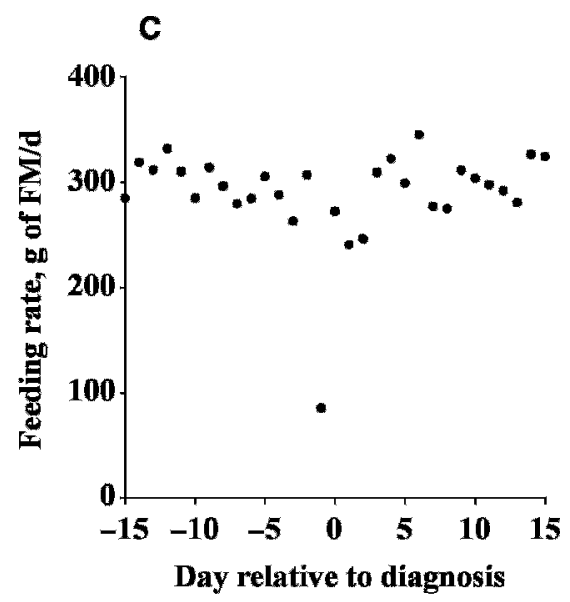

$\mathbf{F}$

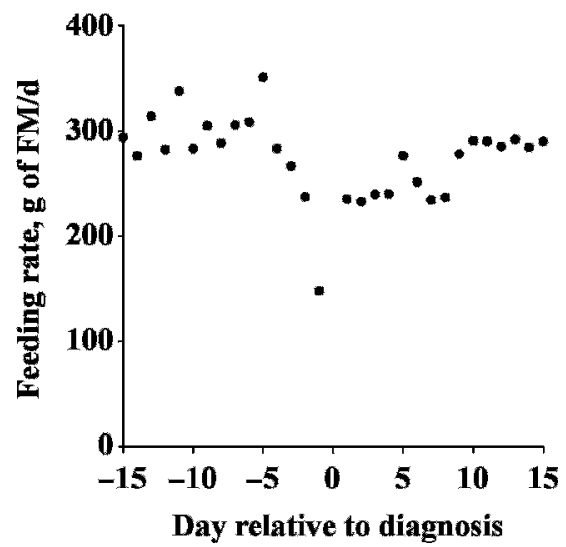

Figure 1. Fresh feed intake, feeding time, and feeding rate of 2 ketotic cows. The cow described in the top panels (A, B, and C) showed a rapid recovery due to calcium borogluconate and dextrose treatment on the day of diagnosis. The cow described in the bottom panels (D, $\mathrm{E}$, and F) was diagnosed but not treated and recovered more slowly. FM = fresh matter.

cows had mastitis due to $E$. coli and another 2 were diagnosed as having teat or udder injury. The rest were all showing local mastitis in 1 or 2 quarters at the time. However, we observed a great variability of responses to udder disorders. Frequently, the day of onset was unclear and statistical analysis would have relied on very subjective estimates. For that reason, no statistical analysis is presented. Only 11 out of 26 cows recorded with mastitis in 1 or 2 quarters showed a noticeable decrease in feed intake and in feeding time, but the remaining 15 did not show any consistent change in feeding behavior characteristics. When changes were noticeable, cows with mastitis in 1 mammary gland showed changes characterized by a short and sudden decrease in feeding time and in feed intake at the day of the diagnosis, whereas feeding rate was not affected. Infection diagnosed as $E$. coli mastitis showed a similar effect as mastitis in a single mammary gland although the recovery period for feed intake and daily feeding time was usually longer.
Chronic Lameness. Table 2 presents the results of the changes in short-term feeding behavior over time for those cows recorded with any kind of chronic locomotion disorder (lame) or their healthy counterparts (nonlame) at the day of checking and trimming. Results are presented as the average slope over the $30 \mathrm{~d}$ before trimming for all lame and nonlame cows, independent of the type of ration fed, because the forage $\times$ lameness status $\times$ time interaction was not significant for any of the analyzed characteristics $(P>0.10)$. Both lame and nonlame cows decreased their intake during this period and the slopes did not differ between them. There was a lameness status $\times$ time interaction on feeding rate and daily feeding time indicating that the change over time (slope) was different between lame and nonlame cows. Lame cows increased their feeding rate during the $30 \mathrm{~d}$ before the day of trimming, whereas nonlame cows did not show any change over time $(P=0.67)$. This increase in feeding rate happened while feeding time decreased in lame cows, with no changes in nonlame 


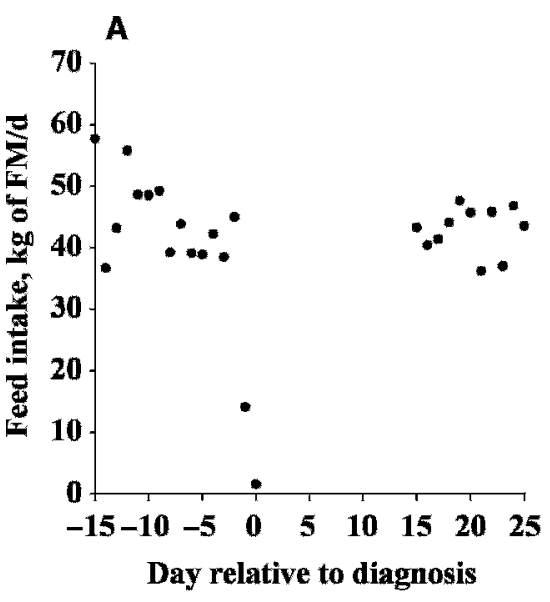

D

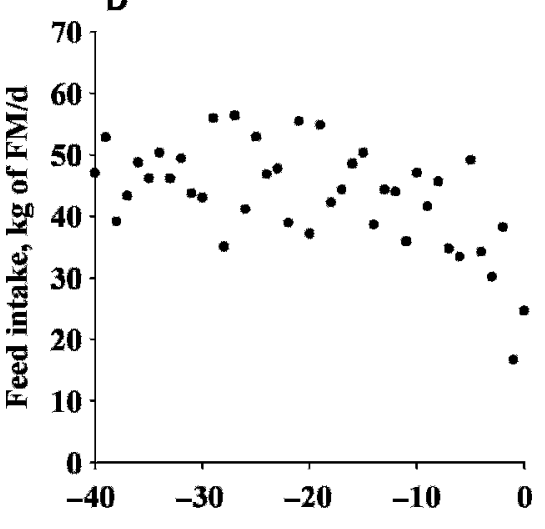

Day relative to diagnosis
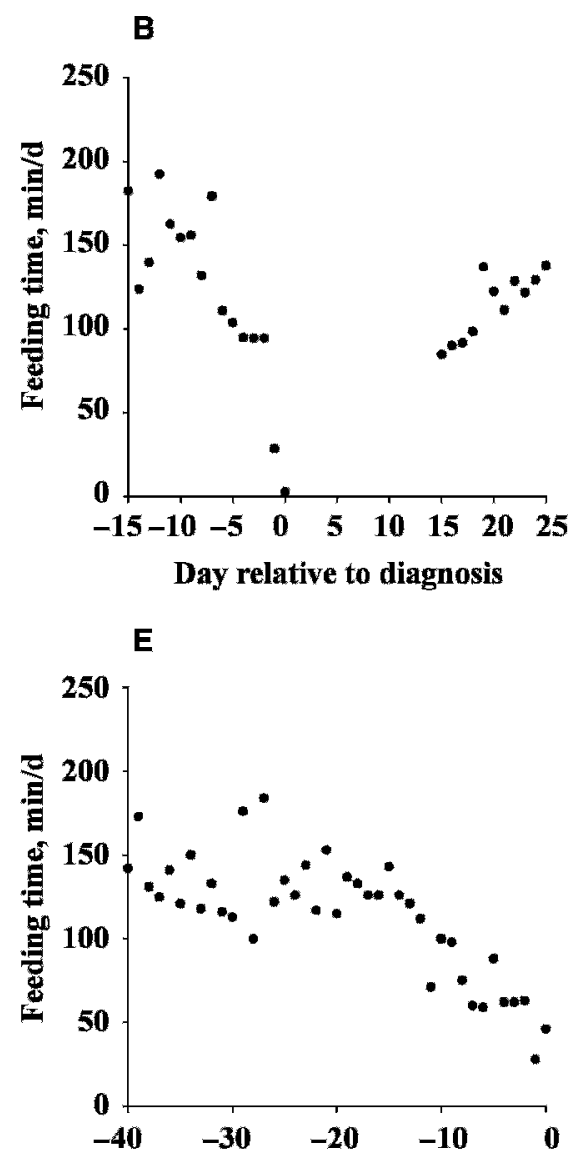

Day relative to diagnosis

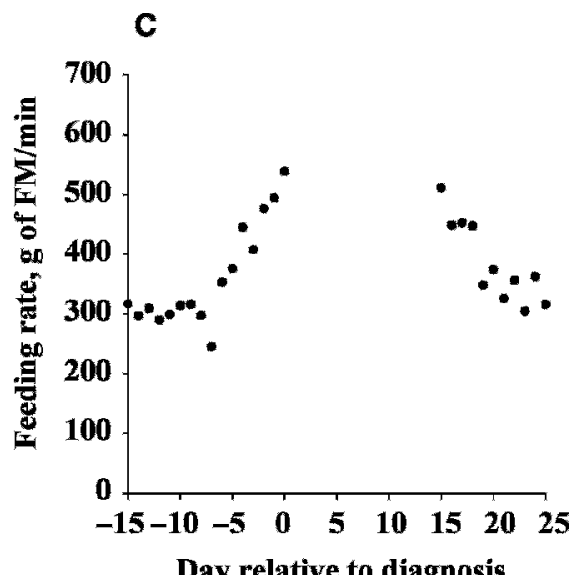

Day relative to diagnosis

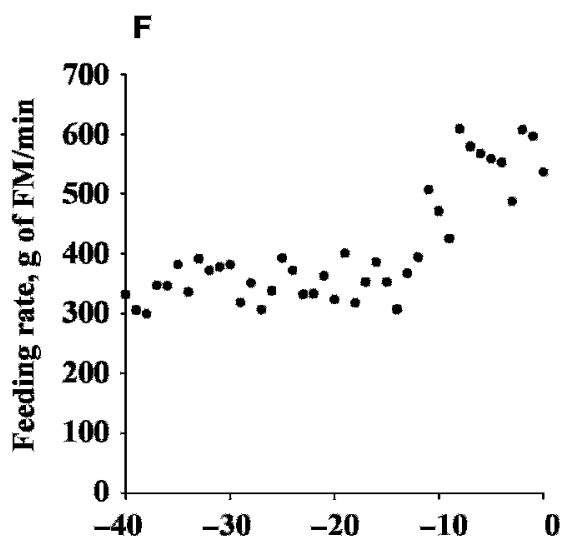

Day relative to diagnosis

Figure 2. Fresh feed intake, feeding time, and feeding rate of 2 cows with locomotory problems. The cow described in the top panels (A, $\mathrm{B}$, and C) was diagnosed with a sole ulcer and was temporarily removed to a sick pen. The cow described in the bottom panels (D, E, and F) was diagnosed with a spinal abscess and was killed after diagnosis. FM = fresh matter.

cows $(P=0.42)$. A typical example of these changes in feed intake, feeding time and feeding rate over before diagnosis and trimming of a lame cow with foul-of-foot is shown in Figures $3 \mathrm{~A}, 3 \mathrm{~B}$, and $3 \mathrm{C}$, respectively; whereas another example of a lame cow with laminitis and interdigital dermatitis is shown in Figures 3D, 3E, and $3 \mathrm{~F}$. No differences in the slopes between lame and nonlame cows $(P=0.59$; Table 2$)$ were observed for the number of meals per day. However, the number of visits per day to the feeders showed a decrease over time for

Table 2. Regression coefficients and standard errors (SE) resulting from linear regression of feeding behavior characteristics for $30 \mathrm{~d}$ before hoof trimming for cows that were subsequently classified as lame or nonlame

\begin{tabular}{|c|c|c|c|c|c|}
\hline \multirow[b]{2}{*}{ Item } & \multicolumn{2}{|l|}{ Lame $(\mathrm{n}=87)$} & \multicolumn{2}{|c|}{ Nonlame $(\mathrm{n}=64)$} & \multirow[b]{2}{*}{$P$-value ${ }^{1}$} \\
\hline & Regression coefficient $^{2}$ & $\mathrm{SE}$ & Regression coefficient & $\mathrm{SE}$ & \\
\hline Feed intake, $\mathrm{kg}$ of $\mathrm{FM}^{3} / \mathrm{d}$ & $-0.047^{*}$ & 0.023 & -0.037 & 0.027 & 0.72 \\
\hline Feeding time, $\min / \mathrm{d}$ & $-0.748^{* * *}$ & 0.099 & -0.093 & 0.117 & $<0.001$ \\
\hline Meal time, $\mathrm{min} / \mathrm{d}$ & $-1.046^{* * *}$ & 0.146 & -0.273 & 0.172 & $<0.001$ \\
\hline Feeding rate, $\mathrm{g}$ of $\mathrm{FM} / \mathrm{min}$ & $0.768 * * *$ & 0.194 & 0.098 & 0.232 & $<0.001$ \\
\hline Meals, n/d & $-0.0094 * *$ & 0.0029 & $-0.0074^{*}$ & 0.0035 & 0.59 \\
\hline Visits, $n / d$ & $-0.347 * * *$ & 0.057 & -0.095 & 0.067 & 0.004 \\
\hline
\end{tabular}

${ }^{1} P$-value of the lameness status $\times$ day interaction.

${ }^{2}$ Regression coefficients are significantly different from zero at $* P<0.05 ; * * P<0.01 ; * * * P<0.001$.

${ }^{3} \mathrm{FM}=$ fresh matter. 


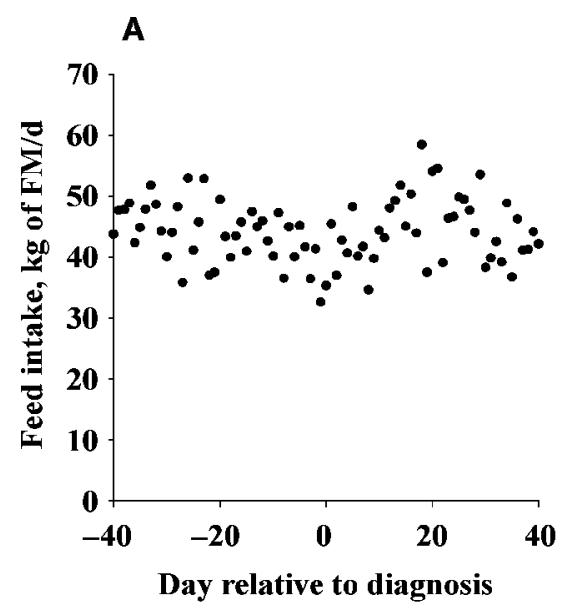

D

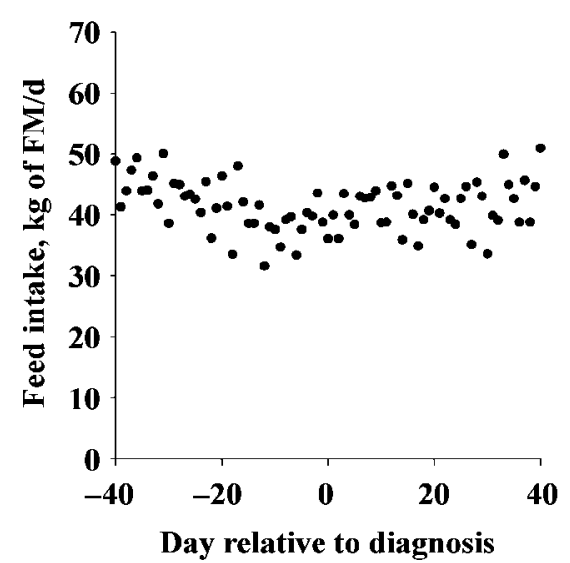

B

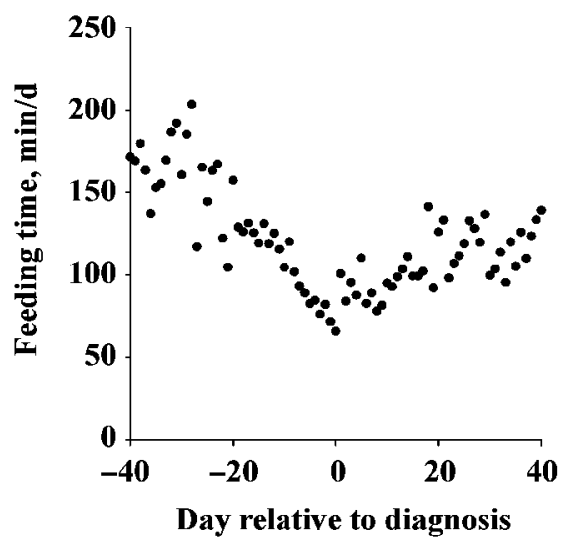

E

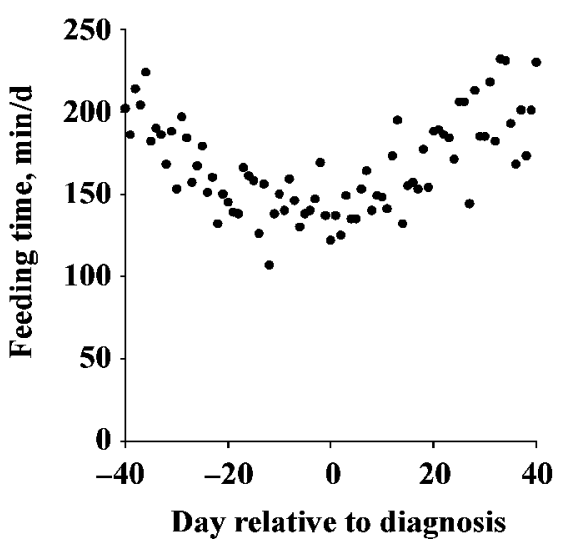

C

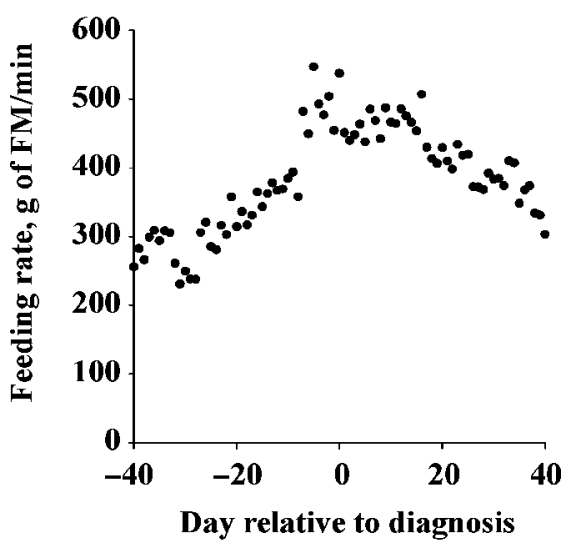

$\mathbf{F}$

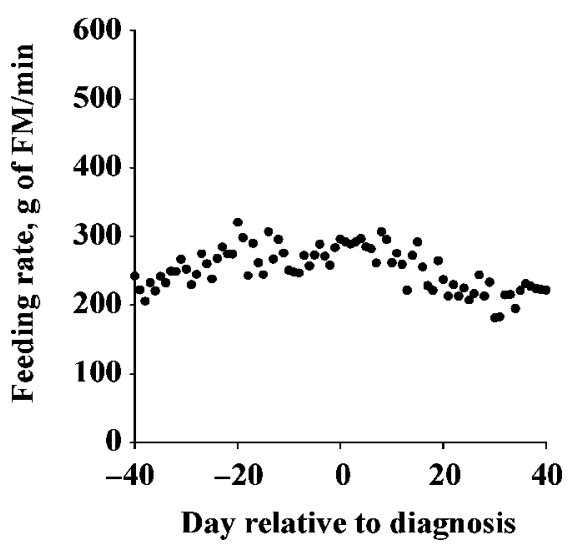

Figure 3. Typical changes in fresh feed intake, feeding time, and feeding rate in the days before and after diagnosis of lameness was made by inspection of the feet ( $\mathrm{d}$ 0). The top panels (A, B and C) show the data of a cow diagnosed with foul of the foot; feet were trimmed and the cow was treated with antibiotics on the day of diagnosis. The bottom panels (D, E, and F) show the data of a cow diagnosed with laminitis and interdigital dermatitis; feet were trimmed on the day of diagnosis but no further treatment was given. FM = fresh matter.

the lame cows $(P<0.001)$ but not for the nonlame cows $(P=0.16)$, resulting in different slopes $(P=0.004)$.

The changes in feeding behavior during the first 30 $\mathrm{d}$ after hoof trimming for lame and nonlame cows are shown in Table 3. The changes in feed intake, feeding time, and feeding rate over time after diagnosis, trimming, and treatment (d 0) with antibiotics of a lame cow is shown in Figures 3A, 3B, and 3C, respectively; whereas changes around trimming in another lame cow with laminitis but with no further veterinary treatment received is shown in Figures 3D, 3E, and 3F. None of the variables tested showed a significant lameness status $\times$ ration forage content $\times$ time (slope) interaction indicating that the changes in feeding behavior were statistically the same for cows in a given lameness status that were consuming either low- or high-forage rations $(P>0.10)$. Thus, data are presented for lame and nonlame cows independent of the diet being fed. The lameness status $\times$ time (slope) after trimming was sig- nificant for fresh feed intake, daily feeding time, daily meal time, feeding rate, and number of visits per day (Table 3). This shows that the changes of these variables after hoof trimming differed between lame and nonlame cows. Fresh feed intake decreased with time after trimming in nonlame cows $(P<0.001)$, whereas the change in intake was not significant for lame cows over the 30 d posttrimming $(P=0.72)$. Daily feeding time $(P=0.07)$ and meal time $(P=0.09)$ showed a tendency to increase throughout the $30 \mathrm{~d}$ posttrimming for lame cows, whereas both characteristics decreased over time in nonlame cows $(P<0.05)$. Lame cows decreased numerically the feeding rate during the $30 \mathrm{~d}$ posttrimming in average, although this slope was not statistically different from zero $(P=0.17)$. In contrast, nonlame cows showed an increase in feeding rate after being trimmed $(P=0.05$; Table 3$)$. The average feeding rate during the $30 \mathrm{~d}$ posttrimming was greater in lame compared with nonlame cows $(300 \pm 17$ vs. $247 \pm 18 \mathrm{~g}$ of FM/ 
Table 3. Regression coefficients and standard errors (SE) resulting from linear regression of feeding behavior characteristics for $30 \mathrm{~d}$ after cows were hoof trimmed and classified as lame or nonlame

\begin{tabular}{|c|c|c|c|c|c|}
\hline \multirow[b]{2}{*}{ Item } & \multicolumn{2}{|l|}{ Lame $(\mathrm{n}=81)$} & \multicolumn{2}{|l|}{ Nonlame $(\mathrm{n}=62)$} & \multirow[b]{2}{*}{$P$-value } \\
\hline & Regression coefficient $^{2}$ & $\mathrm{SE}$ & Regression coefficient & $\mathrm{SE}$ & \\
\hline Feed intake, $\mathrm{kg}$ of $\mathrm{FM}^{3} / \mathrm{d}$ & -0.010 & 0.028 & $-0.124 * * *$ & 0.026 & 0.004 \\
\hline Feeding time, $\mathrm{min} / \mathrm{d}$ & $0.318 \dagger$ & 0.177 & $-0.547 * *$ & 0.171 & $<0.001$ \\
\hline Meal time, min/d & $0.434 \dagger$ & 0.257 & $-0.501^{*}$ & 0.249 & 0.01 \\
\hline Feeding rate, $\mathrm{g}$ of $\mathrm{FM} / \mathrm{min}$ & -0.355 & 0.255 & $0.505^{*}$ & 0.252 & 0.02 \\
\hline Meals, n/d & -0.001 & 0.005 & $0.009^{*}$ & 0.004 & 0.13 \\
\hline Visits, $n / d$ & $0.315 * * *$ & 0.080 & 0.035 & 0.076 & 0.01 \\
\hline
\end{tabular}

min, respectively; $P<0.001$ ) as a result of a significant difference at the start of this period (data not shown).

\section{Changes in Feeding Behavior as a Diagnostic Tool}

Acute Health Problems. Table 4 shows the results of our investigation into whether changes in feeding time can be used as a diagnostic tool to facilitate early detection of acute health problems. For this analysis, "normal feeding time" was defined on the basis of a 7d rolling mean $\pm X$ times the SD, with values for $X$ ranging from 1.5 to 5.0. It was assumed that detection by the algorithm would be known by farm staff $1 \mathrm{~d}$ after the feeding time dropped below the safety margin. The average number of days before diagnosis that a deviation from normal feeding time was detected decreased with increasing values of $X$, as expected. When the algorithm used for detection was set at the mean time of the previous $7 \mathrm{~d}-1.5$ standard deviations, 20 out of 22 cows suffering from ketosis or acute locomotory problems were detected one or more days before identification of the disorder by farm staff. An increase in $X$ to $2.5 \mathrm{SD}$ had limited effects on the power of detection and still allowed early detection of almost all of these cows. However, an increase of the safety margin to 3 $\mathrm{SD}$ or beyond rapidly lead to a lower proportion of cows being detected early (Table 4).

\section{DISCUSSION}

Ketosis was characterized by a rapid decrease of feed intake during the 3 to $5 \mathrm{~d}$ before its detection by farm staff, with near-zero intakes on the day of diagnosis. The number of days in which the negative effects of ketosis on intake were observed agrees with those reported by Bareille et al. (2003), but our estimates on the cumulative DMI losses during these days is greater than the $7.5 \mathrm{~kg}$ of DM reported by these authors. The rapid decrease in feed intake was associated with a decrease in daily feeding time of $45 \mathrm{~min} / \mathrm{d}$ during the days immediately before diagnosis and this characteristic seems, therefore, suitable for use in early detection programs.

Table 4. The number of cows identified by an algorithm with a given number of days before diagnosis of ketosis or acute locomotory disorder by farm staff

\begin{tabular}{llcccccc}
\hline Disorder & Number of days ${ }^{1}$ & $5 \mathrm{SD}$ & $4 \mathrm{SD}$ & $3 \mathrm{SD}$ & $2.5 \mathrm{SD}$ & $2 \mathrm{SD}$ & $1.5 \mathrm{SD}$ \\
\hline Ketosis $(\mathrm{n}=8)$ & Not detected & 5 & 4 & 2 & 0 & 0 & 0 \\
& 0 & 1 & 1 & 2 & 2 & 2 & 1 \\
& 1 & 2 & 3 & 3 & 4 & 4 & 4 \\
& 2 & 0 & 0 & 0 & 1 & 1 & 2 \\
Locomotion $(\mathrm{n}=14)$ & 3 & 0 & 0 & 1 & 1 & 1 & 1 \\
& Not detected & 9 & 6 & 1 & 0 & 0 & 0 \\
& Postdiagnosis & 1 & 2 & 3 & 1 & 1 & 1 \\
& 0 & 0 & 0 & 0 & 1 & 0 & 0 \\
& $1-3$ & 0 & 0 & 2 & 2 & 1 & 1 \\
& $4-6$ & 3 & 3 & 2 & 2 & 4 & 4 \\
\hline
\end{tabular}

\footnotetext{
${ }^{1}$ Number of days in advance that cows were identified by the algorithm compared with identification of the disorder by farm personnel. Identification was by a detection algorithm based on 7-d rolling mean feeding time $-X$ (with $X$ between 1.5 and 5) standard deviations (SD).
} 
In contrast to ketosis, acute locomotion disorders resulted in only a small daily decrease in feed intake before diagnosis. This rate of decline was likely driven by the rapid decrease in feed intake in the last 1 or 2 $\mathrm{d}$ before diagnosis. The effect of acute locomotion disorders was proportionately much greater on feeding time and feeding rate. Animals probably responded to pain by gradually feeding at a faster rate and continued to consume similar amounts of feed during shorter periods. Indeed, feeding rate showed a very consistent increase, up to 2- or 3-fold, with the occurrence of locomotion problems. The equally considerable decrease in daily feeding time showed that it could be a good indicator of this type of disorder. It seems likely that feeding time is a better characteristic for the early identification of acute lameness than milk yield because standing time was previously reported to be greatly decreased with lameness (Hassall et al., 1993), but feed intake and milk yield were only slightly reduced (Bareille et al., 2003). The latter authors reported that clinical cases of lameness associated with hock and foot lesions reduced DMI by 5.6 and $6.4 \mathrm{~kg}$ during 4 and $5 \mathrm{~d}$ before the day of diagnosis, respectively. During these days, milk production was subtly reduced by 1.2 and $3.3 \mathrm{~kg} /$ $\mathrm{d}$, respectively. However, DMI and milk yield were reported to be reduced for at least 2 mo after diagnosis or even for the rest of lactation (Fourichon et al., 1999; Bareille et al., 2003). Because the number of animals in the present study was limited, the type of lameness was not considered as another variable for the analyses. However, different types of locomotion disorders could result in different responses. More research is needed in this area to explore differences in response to different locomotion ailments that may be associated with differences in pain and the way that the animal copes with the disease.

Acute udder disorders were not analyzed in this study because of the great variability in responses, with some cows showing a sharp decrease of feed intake and in feeding time but with a large proportion of cows not showing any changes in feeding behavior. When feed intake and feeding time decreased with the onset of mastitis, the effect was of short duration similar to ketosis, and the recovery after veterinary treatment was rapid. Bareille et al. (2003) reported the onset, based on a negative estimate of DMI, of systemic mastitis and mastitis of one quarter as beginning 5 and $4 \mathrm{~d}$ before the diagnosis, respectively, with a cumulative milk loss of only 6.7 and $1.6 \mathrm{~kg}$. Feeding behavior alone may not be a suitable detection indicator for mastitis because not all types of mastitis lead to reduced feed intake and feeding time, because of differences in the degree of infection or the type of pathogen. Milk production or electrical conductivity by each udder quarter may be a better indicator of mastitis (Frost et al., 1997; Bareille et al., 2003). However, Mottram (1997) stated that milk yield and electrical conductivity are not affected by all types of mastitis, similar to feeding behavior. Systems based on fuzzy logic (e.g., De Mol and Woldt, 2001; Cavero et al., 2006) can use different sources of information for disease detection. In such systems, monitoring of feeding behavior could play a role, in addition to other variables such as milk yield and milk conductivity, to identify more accurately cases of mastitis.

Chronic locomotion disorders produced more gradual changes in feeding behavior characteristics but the cumulative absolute changes due to chronic lameness were often the same as in acute cases. Therefore, we compared the changes in feeding behavior of lame cows with those of nonlame cows as diagnosed at the time of hoof trimming. There is no way of knowing exactly when the conditions diagnosed at trimming started to affect cows. Nocek (1997) and Bergsten (2003) indicated that 2 to 3 mo may be required until foot lesions are visible. Examination of the figures indicated that in many cases changes in feeding behavior lasted $30 \mathrm{~d}$ or longer and therefore we analyzed changes in the 30-d periods before and after trimming. The variation in changes in feeding time by animals that are affected by chronic foot lesions may be related to differences in the development and severity of the disorder. More research is necessary in this field to investigate the possibility of differentiating between locomotory disorders through differences in feeding behavior. However, a feeding behavior monitoring system, and an appropriate methodology of analysis, may be able to detect lame cows before clinical signs become visible either through locomotion impairment or hoof lesions. Feeding behavior could be integrated into automatic monitoring systems in a high-tech environment to improve detection of chronic lameness and welfare of cows through the use of fuzzy logic models such as those described by De Mol and Woldt (2001).

Neither acute nor chronic lameness resulted in great changes in feed intake; however, the day-to-day variability in feed intake generally increased. Daily feeding and meal times and the number of visits to the feeder all decreased before cows were identified as lame. In contrast, the feeding rate of lame cows increased before trimming. No significant changes over time were observed for nonlame cows during the same period, which shows that the long-term changes in feeding behavior are probably due to the locomotion problems detected at the time of trimming. It is also likely that the degree of change is related to differences in the degree of pain suffered by the cow. Because foot and leg disorders cause pain in the cow (Whay et al., 1998) and standing 
will cause discomfort, the cow may try to feed for shorter periods of time and compensate for this by feeding faster than the preferred rate in healthy conditions. O'Callaghan et al. (2003) showed that behavioral scores due to lameness and pedometer activity level were closely associated with the severity of foot lesions because they are indicators of the pain associated with lameness. Other researchers also concluded that claw lesions are painful and cows that suffer from them are reluctant to move and may eat less food (Hassall et al., 1993). Numerically shorter feeding times were also observed when locomotion scores of dairy cows increased (Cook et al., 2004). Similarly, Bach et al. (2007) observed a reduction of total feeding time from 268 to $240 \mathrm{~min} / \mathrm{d}$ as the locomotion score increased from 1 to 5 . In contrast to our results, the number of meals also decreased with increasing locomotion score in that study but DMI $(<1$ $\mathrm{kg} \mathrm{DM} / \mathrm{d})$ and milk production $(<2 \mathrm{~kg} / \mathrm{d})$ decreased only slightly in cows with clinical lameness only. In the present study, the number of visits per day decreased in lame cows during the $30 \mathrm{~d}$ before trimming, which suggests that cows may have switched less often from one feeder to another within a meal because walking was painful. The similar changes in feed intake for lame and nonlame cows in the present study suggests that daily intake of lame cows was not affected by the decrease in feeding time because of the increase in feeding rate. The recorded changes in daily feeding time agree with those observed in daily activity levels with advancing lameness (O'Callaghan et al., 2003). These studies showed a reduction of 24 or $38 \%$ in the average steps per hour, which is in the same direction but proportionally smaller than the reduction in feeding time of lame compared with nonlame cows in our study. Because most of the daily standing time of the cow is spent in feeding activities (Cook et al., 2004), it is likely that feeding time will be one of the activities that is most affected by locomotion disorders.

Many cows doubled or tripled their feeding rate during acute or chronic lameness compared with the rate observed before the disorder occurred. In principle, cows can increase their feeding rate as measured in our intake recording system in 2 ways. The first is by means of a decrease in the time taken to apprehend, chew, and swallow a mouthful of feed per se. The second is by decreasing the proportion of visit duration spent idling instead of actually feeding. The data we collected do not allow us to distinguish between these 2 mechanisms, but both would result in less time required standing to consume a given amount of feed. The increase in feeding rate of lame cows did not differ between cows fed high- or low-forage diets. This shows that even on high-forage diets, cows have the flexibility to substantially increase their feeding rate, which has also been observed to occur as a result of an increase in cow pressure per feeder (Elizalde and Mayne, 1993). Nevertheless, lameness could be more prejudicial, from a welfare point of view, in cows fed high-forage rations because of the longer daily feeding times associated with such rations.

Changes observed after maintenance foot trimming were contradictory. A relief of pain would be expected as a result of trimming and veterinary treatment. However, only some clinical cases causing lameness received veterinary treatment in the present study and most of the cows were only trimmed and not treated. Lame cows showed a decrease in feeding time and an increase in feeding rate during the $30 \mathrm{~d}$ before trimming. These changes were either stabilized (no change over time) or reversed after trimming. This indicates that discomfort was relieved with trimming, which then allowed more comfortable walking and standing. Similar suggestions have been made when, after trimming, test-day milk yield increased (Sogstad et al., 2007), the incidence and duration of clinical lameness was reduced (Manson and Leaver, 1988), or the contact area and the weight-bearing balance among claws was improved (van der Tol et al., 2004). The changes in feeding time and meal time of nonlame cows after trimming are likely directly related to the gradual decrease in feed intake. It is not clear, however, what caused the increase in feeding rate in these cows after trimming.

The final objective of the present study was to test if the changes observed in feeding behavior with the onset of different diseases could be used as a diagnostic tool for the automatic early detection of health disorders through the use of a feeding behavior monitoring system. The most dramatic changes occurred in total feeding time (for ketosis and lameness) and feeding rate (especially for lameness). The latter characteristic, however, is less suitable for on-farm use because it requires knowledge of intake, which is not easily measured on-farm. We chose, therefore, feeding time as the most suitable short-term feeding behavior characteristic for monitoring purposes.

Ketosis can be a target disease for a monitoring system that would allow the detection of sick cows at least $1 \mathrm{~d}$ in advance, thus avoiding major losses of production (Fourichon et al., 1999). After veterinary treatment of ketosis, cows showed a quick recovery in intake, which emphasizes the benefits of detecting this disorder early. Similarly, acute locomotion disorders showed a considerable decrease in daily feeding time during the 7 to $8 \mathrm{~d}$ before diagnosis, which makes this characteristic a good indicator for this type of ailment. The earliest detection of the largest number of affected cows occurred at the lowest safety margin for feeding 
time that we used; that is, the mean of the previous $7 \mathrm{~d}-1.5 \mathrm{SD}$. An increase in the safety margin to mean - 2.5 SD still identified almost all cows well before farm staff identified the disorder. Still wider safety margins (i.e., based on an SD of 3 or larger) resulted in more disorders being identified later or not at all. The analyses suggest, therefore, that a safety margin up to $2.5 \mathrm{SD}$ will lead to a high detection rate with few false negatives. It seems likely that narrow safety margins will lead to false positives; that is, cows that are identified as a result of their normal variation in feeding behavior, not because they suffer from some disorder. The best setting for an early detection algorithm must find the optimum safety margin; that is, the margin that results in the best combination for maximizing detection of affected cows and minimizing false positives at the same time. The best setting of such an algorithm will depend on the actual variation in feeding time observed in healthy and sick cows in a given herd.

\section{CONCLUSIONS}

Our analysis shows that cows with different disorders modify their short-term feeding behavior in characteristic ways. A monitoring system based on the mean and SD of feeding time of the individual cow can identify such changes for affected cows. It is expected that inspection of such cows by farm staff will lead to earlier detection of a number of disorders, particularly ketosis and lameness. In combination with other monitoring systems such a system may also assist in early identification of other disorders such as mastitis. Early detection and veterinary treatment of such disorders is expected to be beneficial, not only for cow welfare, but also for farm profitability.

\section{ACKNOWLEDGMENTS}

The first author gratefully acknowledges the studentship from the Spanish MECD (FPU AP20023344), and the British Society of Animal Science (Penicuik, UK) and the Scottish Agricultural College (Edinburgh, UK) for their valuable help and encouragement.

\section{REFERENCES}

Bach, A., M. Dinarés, M. Devant, and X. Carré. 2007. Associations between lameness and production, feeding and milking attendance of Holstein cows milked with an automatic milking system. J. Dairy Res. 74:40-46.

Bareille, N., F. Beaudeau, S. Billon, A. Robert, and P. Faverdin. 2003. Effects of health disorders on feed intake and milk production in dairy cows. Livest. Prod. Sci. 83:53-62.

Bergsten, C. 2003. Causes, risk factors, and prevention of laminitis and related claw lesions. Acta Vet. Scand. Suppl. 98:157-166.
Cavero, D., K. H. Tolle, C. Buxade, and J. Krieter. 2006. Mastitis detection in dairy cows by application of fuzzy logic. Livest. Sci. 105:207-213.

Cook, N. B., T. B. Bennett, and K. V. Nordlund. 2004. Effect of free stall surface on daily activity patterns in dairy cows with relevance to lameness prevalence. J. Dairy Sci. 87:2912-2922.

De Mol, R. M., and W. E. Woldt. 2001. Application of fuzzy logic in automated cow status monitoring. J. Dairy Sci. 84:400-410.

Elizalde, H. F., and C. S. Mayne. 1993. The effect of degree of competition per feed space on the dry matter intake and eating behaviour of dairy cows offered grass silage. Pages 137-138 in Proc. 3rd Res. Conf., Br. Grassl. Soc. Greenmount College, Antrim, UK.

FAWC. 1997. Report on the Welfare of Dairy Cattle. Farm Animal Welfare Council (FAWC), London, UK.

Fleischer, P., M. Metzner, M. Beyerbach, M. Hoedemaker, and W. Klee. 2001. The relationship between milk yield and the incidence of some diseases in dairy cows. J. Dairy Sci. 84:2025-2035.

Fourichon, C., H. Seegers, N. Bareille, and F. Beaudeau. 1999. Effects of disease on milk production in the dairy cow: A review. Prev. Vet. Med. 41:1-35.

Frost, A. R., C. P. Schofield, S. A. Beaulah, T. T. Mottram, J. A. Lines, and C. M. Wathes. 1997. A review of livestock monitoring and the need for integrated systems. Comp. Electr. Agric. 17:139-159.

Hassall, S. A., W. R. Ward, and R. D. Murray. 1993. Effects of lameness on the behaviour of cows during the summer. Vet. Rec. 132:578-580.

Huzzey, J. M., D. M. Veira, D. M. Weary, and M. A. G. von Keyserlingk. 2007. Prepartum behavior and dry matter intake identify dairy cows at risk for metritis. J. Dairy Sci. 90:3220-3233.

Kossaibati, M. A., and R. J. Esslemont. 1997. The costs of production diseases in dairy herds in England. Vet. J. 154:41-51.

Maatje, K. J., J. Verhoeff, W. D. J. Kremer, A. L. M. Cruijsen, and T. S. G. A. M. van den Ingh. 1993. Automated feeding of milk replacer and health control of group-housed veal calves. Vet. Rec. 133:266-270.

Manson, F. J., and J. D. Leaver. 1988. The influence of concentrate amount on locomotion and clinical lameness in dairy cattle. Anim. Prod. 47:185-190.

Mottram, T. 1997. Automatic monitoring of the health and metabolic status of dairy cows. Livest. Prod. Sci. 48:209-217.

Nocek, J. E. 1997. Bovine acidosis: Implications on laminitis. J. Dairy Sci. 80:1005-1028.

O'Callaghan, K. A., P. J. Cripps, D. Y. Downham, and R. D. Murray. 2003. Subjective and objective assessment of pain and discomfort due to lameness in dairy cattle. Anim. Welf. 12:605-610.

Quimby, W. F., B. F. Sowell, J. G. P. Bowman, M. E. Branine, M. E. Hubbert, and H. W. Sherwood. 2001. Application of feeding behaviour to predict morbidity of newly received calves in a commercial feedlot. Can. J. Anim. Sci. 81:315-320.

Rajala-Schultz, P. J., Y. T. Gröhn, and C. E. McCulloch. 1999. Effects of milk fever, ketosis, and lameness on milk yield in dairy cows. J. Dairy Sci. 82:288-294.

Shearer, J., E. Belknap, S. Berry, C. Guard, K. Hoblet, E. Hovingh, G. Kirksey, A. Langill, and S. van Amstel. 2002. The standardization of input codes for capture of lameness data in dairy records. Pages 346-349 in Proc. 12th Int. Symp. Lameness in Ruminants, Orlando, FL. Online. http://www.ivis.org/ proceedings/RumLameness/2002/toc.asp\#state2 Accessed Apr. 20, 2007.

Sogstad, A. M., O. Østerås, T. Fjeldaas, and A. O. Refsdal. 2007. Bovine claw and limb disorders at claw trimming related to milk yield. J. Dairy Sci. 90:749-759.

Svensson, C., and M. B. Jensen. 2007. Identification of diseased calves by use of data from automatic milk feeders. J. Dairy Sci. 90:994-997.

Thomsen, P. T., A. M. Kjeldsen, J. T. Sørensen, and H. Houe. 2004. Mortality (including euthanasia) among Danish dairy cows (1990-2001). Prev. Vet. Med. 62:19-33.

Tolkamp, B. J., R. J. Dewhurst, N. C. Friggens, I. Kyriazakis, R. F. Veerkamp, and J. D. Oldham. 1998a. Diet choice by dairy cows. 
1. Selection of protein content during the first half of lactation. J. Dairy Sci. 81:2657-2669.

Tolkamp, B. J., N. C. Friggens, G. C. Emmans, I. Kyriazakis, and J. D. Oldham. 2002. Meal patterns of dairy cows consuming diets with a high or a low ratio of concentrate to grass silage. Anim. Sci. 74:369-382.

Tolkamp, B. J., and I. Kyriazakis. 1997. Measuring diet selection in dairy cows: Effect of training on choice of dietary protein level. Anim. Sci. 64:197-207.

Tolkamp, B. J., and I. Kyriazakis. 1999. To split behaviour into bouts, log-transform the intervals. Anim. Behav. 57:807-817.

Tolkamp, B. J., I. Kyriazakis, J. D. Oldham, M. Lewis, R. J. Dewhurst, and J. R. Newbold. 1998b. Diet choice by dairy cows. 2 . Selection for metabolizable or for ruminally degradable protein? J. Dairy Sci. 81:2670-2680.

Tolkamp, B. J., D. P. Schweitzer, and I. Kyriazakis. 2000. The biologically relevant unit for the analysis of short-term feeding behavior of dairy cows. J. Dairy Sci. 83:2057-2068.
Urton, G., M. A. G. von Keyserlink, and D. M. Weary. 2005. Feeding behaviour identifies dairy cows at risk for metritis. J. Dairy Sci. 88:2843-2849.

van der Tol, P. P. J., S. S. van der Beek, J. H. M. Metz, E. N. Noordhuizen-Stassen, W. Back, C. R. Braam, and W. A. Weijs. 2004. The effect of preventive trimming on weight bearing and force balance on the claws of dairy cattle. J. Dairy Sci. $87: 1732-1738$

Veerkamp, R. F., G. Simm, and J. D. Oldham. 1995. Genotype by environment interactions: experience from Langhill. Pages 5966 in Breeding and Feeding the High Genetic Merit Cow. T. L. J. Lawrence, F. J. Gordon and A. Carson, ed. Br. Soc. Anim. Sci. Occ. Publ. No.19, Edinburgh, UK.

Whay, H. R., A. E. Waterman, A. J. F. Webster, and J. K. O'Brien. 1998. The influence of lesion type on the duration of hyperalgesia associated with hindlimb lameness in dairy cattle. Vet. J. $156: 23-29$

Yeates, M. P., B. J. Tolkamp, D. J. Allcroft, and I. Kyriazakis. 2001. The use of mixed distribution models to determine bout criteria for analysis of animal behaviour. J. Theor. Biol. 213:413-425. 